\title{
Parasitism of house fly (Musca domestica) pupae by four species of Pteromalidae (Hymenoptera): effects of host-parasitoid densities and host distribution
}

\author{
J. A. MANN, R. E. STINNER and R. C. AXTELL \\ Department of Entomology, North Carolina State University, Raleigh, North Carolina, U.S.A.
}

\begin{abstract}
Parasitoid-induced mortality of house fly, Musca domestica L., pupae and parasitoid progeny emergence by four species of pteromalid parasitoids, Muscidifurax raptor Girault \& Sanders, M.zaraptor Kogan \& Legner, Spalangia cameroni Perkins and S.endius Walker, were determined for a $24 \mathrm{~h}$ exposure period using parasitoid: host ratios ranging from 1:2 to $1: 50$. When the number of parasitoids was held constant $(n=5)$ and the numbers of hosts varied, and when the number of hosts was held constant $(n=100)$ and the number of parasitoids varied, both the number of pupae killed per parasitoid and the number of parasitoid progeny per parasitoid increased with increasing parasitoid:host ratios to reach an upper limit asymptotically. Maximum values were, respectively: M.raptor (14.7, 11.1), M.zaraptor (12.3, 9.3), S.cameroni $(16.9,5.5)$, S.endius $(14.8,9.7)$ with no consistent effects attributed to parasitoid interference.

For M.raptor and S.cameroni at parasitoid:host ratios of 1:10, the pupal mortality and progeny emergence were determined for a $24 \mathrm{~h}$ exposure period when hosts were distributed in poultry manure at four levels of aggregation ranging from clumped to uniform. Pupal mortality was least in clumped distributions, while parasitoid progeny emergence was not significantly different.
\end{abstract}

Key words. Muscidifurax raptor, Muscidifurax zaraptor, Spalangia cameroni, Spalangia endius, house fly, Musca domestica, Pteromalidae.

\section{Introduction}

In confined animal production systems, the house fly, Musca domestica L., is a major pest, and fly management programmes are now being encouraged to integrate cultural and biological control methods (Axtell, 1986a, b; Patterson \& Rutz, 1986). Pteromalid parasitoids of house fly

Correspondence: Dr R. C. Axtell, Department of Entomology, Box 7613, North Carolina State University, Raleigh, NC 27695-7613, U.S.A. pupae are considered to be important biological control agents in these systems, although quantitative data on the host:parasitoid interactions are limited. The level of mortality inflicted on a host population is determined primarily by the response of the parasitoid to host density (functional response; Holling, 1959), while population stability is maintained as a result of both density-dependent parasitoid progeny production and parasitoid-inflicted host mortality (DeBach \& Smith, 1941; Hassel \& Waage, 1984; Holling, 1959). Also contributing to the 
levels of parasitism are the influence of spatially varying patterns of host distribution and the influence of density-dependent parasitoid interference, which may decrease searching efficiency and/or increase parasitoid dispersal (Walde \& Murdoch, 1988).

DeBach \& Smith (1941) showed that, in two species of Pteromalidae, the number of hosts attacked per parasitoid increased with host density to approach a fixed limit asymptotically. This has since been described in Spalangia endius Walker (Ables \& Shepard, 1974; Legner, 1967; Morgan et al., 1979a), S.cameroni Perkins (Legner, 1967) and Muscidifurax raptor Girault \& Sanders (Ables \& Shepard, 1974; Legner, 1967; Morgan et al., 1979b). Intraspecific parasitoid interference has been shown to reduce individual parasitoid efficiency in S.endius and M.raptor at increasing host densities (Ables \& Shepard, 1974). While response to host spatial distribution has differed among pteromalid species, no significant differences were found in host mortality by N.vitripennis (Walker) at different levels of host aggregation (Jones \& Turner, 1987). Higher levels of host mortality in clumped distributions than in linear distributions were observed for S.drosophilae Ashmead (Legner, 1969). Based on the above reports, it is risky to compare species responses and extrapolate to field conditions because the experiments were conducted with different methods and in artificial conditions (in vials with only fly pupae and parasitoids present, but no manure).

Results are presented here for experiments in which Muscidifurax raptor and M.zaraptor Kogan \& Legner were compared with Spalangia cameroni and S.endius under standardized conditions (fly pupae buried in dry poultry manure to incorporate an element of searching and simulate the situation in poultry houses) in order to determine (1) parasitoid response to host density, (2) modifications of this response due to intraspecific parasitoid interference, and (3) the effect of host aggregation on host attack by M.raptor and S.cameroni.

\section{Materials and Methods}

House fly pupae of a known age were obtained by using a metal sieve ( $2.0 \mathrm{~mm}$ openings) to separate larvae from pupae at known intervals of time. The pupae used in the experiments were $24-48 \mathrm{~h}$ old and, based on measured aliquots, were $5.6-5.8 \mathrm{~mm}$ long $\times 2.3-2.5 \mathrm{~mm}$ diameter, and weighed $16-18 \mathrm{mg}$.

The stock cultures of parasitoids were maintained on house fly pupae in cages held at 27 $\pm 3^{\circ} \mathrm{C}, 70 \%$ r.h. and $14 \mathrm{~L}: 10 \mathrm{D}$. The parasitoid cultures were derived from different sources. Adult parasitoids (c. 100), collected in 1987 from poultry houses in North Carolina (N.C.) were used to established the $S$.cameroni culture. The M.raptor culture originally established in 1982 from adults collected in N.C., was augmented by the addition of about 100 adults collected from poultry houses in N.C. in 1987. The culture of M.zaraptor, originating near Denver, Colorado, U.S.A., was derived from a culture obtained in 1983 from E. F. Legner, University of California, Riverside. Identification of M.raptor and M.zaraptor was verified by Dr E. Grissell, U.S.D.A., Systematic Entomology Laboratory, Smithsonian Institution, Washington, D.C. The culture of S.endius was obtained in 1978 from P. B. Morgan, U.S.D.A., Gainesville, Florida, U.S.A. The experiments reported herein were conducted in 1987 and 1988. Voucher specimens of these species have been placed in the Department of Entomology Insect Collection, NCSU, Raleigh, N.C., U.S.A.

Host and parasitoid densities. Transparent plastic cups were the standard exposure chambers used in all experiments. In the first experiment the number of parasitoids was held constant and the number of fly pupae varied. Fly pupae (10, $50,100,150$ or 200$)$ were placed in plastic mesh bags (diameter $5.5 \mathrm{~cm}$, mesh openings $1.5 \mathrm{~mm}$ ). Each bag was placed in a cup (height $11 \mathrm{~cm}$, volume $360 \mathrm{ml}$ ) on top of $7 \mathrm{~cm}$ dry fly rearing medium (CSMA medium, Ralston Purina Co., St Louis, Mo., U.S.A.), and covered to a depth of $1.5 \mathrm{~cm}$ with dry $(10 \%$ moisture) poultry manure (surface area $23.8 \mathrm{~cm}^{2}$ ) which had been sieved and frozen for $48 \mathrm{~h}$. Using an aspirator, five female parasitoids were removed at random from the rearing cage, and introduced into each cup. Controls for each density were held without parasitoids. After $24 \mathrm{~h}$ at $27^{\circ} \mathrm{C}$, the fly pupae were removed from the mesh bag, sieved (mesh openings $1.7 \mathrm{~mm}$ ) to separate the parasitoids, transferred to covered plastic cups, and held at $27^{\circ} \mathrm{C}, 70 \%$ r.h., $14 \mathrm{~L}: 10 \mathrm{D}$ for $2-3$ weeks (until emergence of adult parasitoids was complete). After emergence was complete, the flies and 
parasitoids were counted. For each species, this experiment was replicated six times (two replicates on three different days for M.raptor, $M$.zaraptor and S.cameroni and three replicates on two different days for S.endius).

For the second experiment the same exposure techniques were used for the four species of parasitoids except the number of fly pupae was held constant and the number of parasitoids varied. Each cup contained 100 fly pupae in a mesh bag and $0,2,5,7,10$ or 20 female parasitoids. There were six replicates for each Muscidifurax species and seven for each Spalangia species carried out on three different days for each species.

In both sets of experiments, fly mortality in the controls $(0-10 \%)$ was used to correct the percent parasitoid induced pupal mortality (Abbott, 1925). Percentage progeny emergence was calculated as the percentage of exposed pupae which yielded parasitoid progeny, on the assumption that only one parasitoid emerged per pupa. Residual mortality was defined as pupal mortality due to superparasitism, hostfeeding or unsuccessful parasitism and was calculated as the difference between corrected per cent fly mortality and percentage progeny emergence. The number of pupae killed per parasitoid and the number of parasitoid progeny per parasitoid were also calculated. Means for each of these five variables were analysed using a two-way analysis of variance and mean separations were determined using Tukey's procedure (PROC GLM; SAS Institute, 1982).

Host aggregation. Host mortality and progeny emergence were estimated at four levels of host aggregation using S.cameroni and M.raptor. Experimental arenas consisted of sleeved plexiglass cages $(33 \times 50 \times 33 \mathrm{~cm} \mathrm{ht})$ with windows $\left(20 \mathrm{~cm}^{2}\right)$ covered with wire mesh $(0.2 \mathrm{~mm}$ openings) for ventilation, and false floor of polystyrene having twenty-four equally spaced 5.5 $\mathrm{cm}$ diameter holes in six rows of four each. Twenty-four plastic cups (height $7 \mathrm{~cm}$; diameter $5.5 \mathrm{~cm}$ ) were filled to a depth of $5.5 \mathrm{~cm}$ with dry CSMA fly rearing medium and inserted in the holes such that the cup lip was level with the top of the false floor. Fly pupae in a circular $(5 \mathrm{~cm})$ plastic mesh bag (mesh openings $1.5 \mathrm{~mm}$ ) were placed on top of the medium in some of the cups and all of the cups filled with dry poultry manure and dry manure spread over the false floor so that the cups were no longer visible. To achieve four levels of pupal aggregation in the arenas, 240 fly pupae were equally divided among each of $1,6,12$ or 24 plastic mesh bags. For the highest level of aggregation (distribution I), the bag containing 240 pupae was placed in one of the central cups. At the lowest level of aggregation (distribution IV) one bag containing ten pupae was placed in each of the twenty-four cups. At intermediate levels (distribution II with six bags each containing forty pupae and distribution III with twelve bags each containing twenty pupae) the bags of pupae were randomly assigned to cups.

Twenty-four female parasitoids were randomly selected and aspirated from the rearing cages and introduced into the centre of each arena. A control arena corresponding to each distribution was prepared in the same way but no parasitoids were added. After $24 \mathrm{~h}$ exposure to the parasitoids, the pupae were removed from each cup, sieved to remove stray parasitoids, and held in plastic cups at $27 \pm 2^{\circ} \mathrm{C}, 70 \%$ r.h., 14L:10D for $2-3$ weeks until parasitoid emergence was complete. Then the flies and parasitoids were counted. For each species, each distribution was tested ten times on five different days $(n=10)$ with trials for distributions I and IV being run on different days than distributions II and III.

Pupal mortality in the controls $(0-20 \%)$ was used to correct per cent parasitoid induced pupal mortality (Abbott, 1925) per cage for each distribution. Percentage progeny emergence and percentage residual mortality were determined as previously described.

\section{Results}

\section{Host density}

When the number of hosts exposed to a constant number (five) of parasitoids was increased from ten to 200 , the percentage pupal mortality (parasitoid induced) and the percentage parasitoid progeny emergence decreased as the number of hosts increased, while the number of pupae killed per parasitoid and the parasitoid progeny per parasitoid increased (Table 1). The range of percentage pupal mortalities at densities of 10-200 pupae per cup was 93.2-30.6 (M.raptor), 100-29.9 (M.zaraptor), 98.2-24.7 (S.cameroni) and 89.8-37.9 (S.endius). At densities of 50-150 pupae per cup, the percent- 
Table 1. Mean ( \pm SD) pupal mortality and parasitoid progeny emergence after house fly pupae were exposed for $24 \mathrm{~h}$ to a constant number ( $n=5$ females) of four species of Pteromalidae.

\begin{tabular}{|c|c|c|c|c|c|c|c|}
\hline \multirow[b]{2}{*}{ Species } & \multirow[b]{2}{*}{$\begin{array}{l}\text { Pupal } \\
\text { density }\end{array}$} & \multirow[b]{2}{*}{$\begin{array}{l}\text { Parasitoid: } \\
\text { host ratio }\end{array}$} & \multicolumn{3}{|c|}{ Mean $\%$ of host pupae exposed* } & \multicolumn{2}{|c|}{ Mean no. per parasitoid * } \\
\hline & & & $\begin{array}{l}\text { Pupal mortality } \\
\text { (A) }\end{array}$ & $\begin{array}{l}\text { Parasitoid progeny } \\
\text { (B) }\end{array}$ & $\begin{array}{l}\text { Residual mortality } \\
\text { (A-B) }\end{array}$ & $\begin{array}{l}\text { Pupae } \\
\text { killed }\end{array}$ & $\begin{array}{l}\text { Parasitoid } \\
\text { progeny }\end{array}$ \\
\hline \multirow[t]{3}{*}{ M.raptor } & 10 & $1: 2$ & $93.2 \pm 5.1^{\mathrm{a}}$ & $41.7 \pm 10.1^{\mathrm{ab}}$ & $51.5 \pm 9.8^{\mathrm{a}}$ & $1.8 \pm 0.1^{\mathrm{c}}$ & $0.8 \pm 0.2^{\mathrm{b}}$ \\
\hline & 50 & $1: 10$ & $62.8 \pm 8.2^{\mathrm{b}}$ & $53.3 \pm 8.4^{\mathrm{a}}$ & $9.5 \pm 1.1^{\mathrm{b}}$ & $6.2 \pm 0.8^{\mathrm{b}}$ & $5.3 \pm 0.8^{\mathrm{a}}$ \\
\hline & 100 & $1: 20$ & $43.3 \pm 5.5^{\mathrm{bc}}$ & $38.2 \pm 6.6^{\mathrm{abc}}$ & $5.1 \pm 5.3^{\mathrm{b}}$ & $8.5 \pm 1.1^{\mathrm{ab}}$ & $6.7 \pm 0.8^{\mathrm{a}}$ \\
\hline \multirow[t]{5}{*}{ M.zaraptor } & 10 & $1: 2$ & $100.0 \pm 0.0^{\mathrm{a}}$ & $96.7 \pm 2.1^{\mathrm{a}}$ & $3.3 \pm 2.1^{\mathrm{b}}$ & $2.0 \pm 0.0^{\mathrm{b}}$ & $1.9 \pm 0.1^{\mathrm{b}}$ \\
\hline & 50 & $1: 10$ & $88.7 \pm 3.5^{\mathrm{a}}$ & $76.0 \pm 2.2^{\mathrm{b}}$ & $12.7 \pm 1.7^{\mathrm{ab}}$ & $8.6 \pm 0.3^{\mathrm{a}}$ & $7.6 \pm 0.2^{\mathrm{a}}$ \\
\hline & 100 & $1: 20$ & $63.2 \pm 5.2^{\mathrm{b}}$ & $46.7 \pm 4.5^{\mathrm{c}}$ & $16.5 \pm 3.0^{\mathrm{a}}$ & $12.3 \pm 1.0^{\mathrm{a}}$ & $9.3 \pm 0.9^{\mathrm{a}}$ \\
\hline & 150 & $1: 30$ & $40.0 \pm 3.8^{c}$ & $28.1 \pm 3.4^{\mathrm{d}}$ & $11.9 \pm 1.1^{\mathrm{ab}}$ & $11.7 \pm 1.1^{\mathrm{a}}$ & $8.4 \pm 1.0^{\mathrm{a}}$ \\
\hline & 200 & $1: 40$ & $29.9 \pm 6.5^{\mathrm{c}}$ & $15.5 \pm 4.3^{\mathrm{d}}$ & $14.4 \pm 4.6^{\mathrm{a}}$ & $11.7 \pm 2.6^{\mathrm{a}}$ & $6.2 \pm 1.7^{\mathrm{a}}$ \\
\hline S.cameroni & 10 & $1: 2$ & $98.2 \pm 1.8^{\mathrm{a}}$ & $51.7 \pm 12.8^{\mathrm{a}}$ & $46.5 \pm 12.0^{\mathrm{a}}$ & $1.8 \pm 0.1^{\mathrm{c}}$ & $1.0 \pm 0.3^{\mathrm{b}}$ \\
\hline \multirow[t]{5}{*}{ S.endius } & 10 & $1: 2$ & $89.8 \pm 5.3^{\mathrm{a}}$ & $8.1 \pm 4.0^{\mathrm{b}}$ & $8.1 \pm 4.0^{\mathrm{b}}$ & $1.8 \pm 0.1^{\mathrm{c}}$ & $1.6 \pm 0.1^{\mathrm{b}}$ \\
\hline & 50 & $1: 10$ & $81.6 \pm 3.8^{\mathrm{a}}$ & $26.3 \pm 4.2^{\mathrm{a}}$ & $26.3 \pm 4.2^{\mathrm{a}}$ & $8.0 \pm 0.4^{\mathrm{b}}$ & $5.5 \pm 0.4^{\mathrm{ab}}$ \\
\hline & 100 & $1: 20$ & $70.1 \pm 3.9^{\mathrm{a}}$ & $21.8 \pm 2.5^{\mathrm{ab}}$ & $21.8 \pm 2.5^{\mathrm{ab}}$ & $13.7 \pm 0.8^{\mathrm{a}}$ & $9.7 \pm 0.9^{\mathrm{a}}$ \\
\hline & 150 & $1: 30$ & $48.1 \pm 4.6^{b}$ & $17.0 \pm 2.0^{\mathrm{ab}}$ & $17.0 \pm 2.0^{\mathrm{ab}}$ & $14.1 \pm 1.4^{\mathrm{a}}$ & $9.3 \pm 1.4^{\mathrm{a}}$ \\
\hline & 200 & $1: 40$ & $37.9 \pm 4.6^{\mathrm{b}}$ & $21.3 \pm 5.9^{\mathrm{ab}}$ & $21.3 \pm 5.9^{\mathrm{ab}}$ & $14.8 \pm 1.8^{\mathrm{a}}$ & $6.6 \pm 1.3^{\mathrm{a}}$ \\
\hline
\end{tabular}

* Means followed by the same letters in a column within a species were not significantly different $(P<0.05$, Tukey's procedure). 
age residual mortality was higher with Spalangia species (S.cameroni 16.4-38.9; S.endius 17.026.3) than with Muscidifurax species (M.raptor 5.1-9.5; M.zaraptor 11.9-16.5). The percentage residual mortality at the lowest host density was significantly greater than at the higher host density with S.cameroni. At the lowest host density the percentage residual mortality was significantly lower in M.zaraptor (3.3) but significantly higher in M.raptor (51.5).

There was no significant increase in the number of pupae killed per parasitoid at densities greater than 100 hosts per cup. Similar levels of pupae killed per parasitoid were observed in all four species. Parasitoid progeny per parasitoid increased with a corresponding increase in host densities up to 100 hosts at host densities of ten and fifty pupae per cup, before leveling off, in all species. Maximum progeny emergence per parasitoid was 9.3 for M.zaraptor, 9.7 for S.endius, 6.8 for M.raptor and 5.5 for S.cameroni.

\section{Parasitoid density}

For the four species of parasitoids, the percentage pupal mortality and percentage parasitoid progeny emergence was lower with low parasitoid densities than with high densities (Table 2). The number pupae killed per parasitoid was greater at low densities of all species except $S$.endius. The ranges of percentage pupal mortality at parasitoid densities of 2-20 female parasitoids per cup were similar in M.raptor (29.5-90.7), M.zaraptor (23.2-96.4) and S.cameroni (33.9-92.3), but slightly lower in S.endius (17.0-85.0). Percentage progeny emergence was similar in Muscidifurax species (M.raptor 22.2-69.8; M.zaraptor 18.3-74.8) and S.endius (12.0-63.4), but slightly lower in S.cameroni (11.0-47.3). In all species, percentage residual mortality increased with parasitoid density. Values were higher in S.cameroni than the other species.

The number of pupae killed per parasitoid ranged from 14.7 to 4.5 for M.raptor, from 11.6 to 4.8 for M.zaraptor, from 16.9 to 4.6 for S.cameroni and from 8.5 to 4.3 for S.endius with 2-20 parasitoids per cup. Progeny emergence per parasitoid reached higher maximum values in Muscidifurax species (M.raptor 11.1; M.zaraptor 9.2) than in Spalangia species (S.cameroni 5.5 ; S.endius 6.0). However, values of both pupal mortality per parasitoid and progeny per parasitoid at the lowest parasitoid density (two parasitoids per cup) had high standard errors, reflecting individual variation in ovipositing females. In S.endius, variability was high in comparison to other species for all values.

\section{Host aggregation}

For M.raptor the percentage pupal mortality and number of pupae killed per parasitoid were significantly lower when hosts were clumped than at any other levels of less host aggregation (Table 3). For S.cameroni the percentage pupal mortality, number of pupae killed per parasitoid, and percentage residual mortality were lowest when hosts were clumped and significantly different from the values for intermediate levels of aggregation but not from the values for the lowest level of aggregation. The progeny emergence of both species was not significantly different at any host distribution.

\section{Discussion}

The factors affecting host abundance may be thought of in terms of the number of hosts killed by the parasitoids as affected by the host density (functional response) and the size of the regulating parasitoid population as influenced by the host availability (numerical response) (Hassel, 1978). In our experiments using variable densities of host pupae, all four species exhibited an asymptotic increase in the number of pupae killed per parasitoid and the number of parasitoid progeny emerging per parasitoid. In similar experiments, using M.raptor, S.cameroni and S.endius, Legner (1967) found that progeny emergence per parasitoid began to plateau at parasitoid:host ratios of $c$. 1:20, while Morgan et al. (1979a, b) reported that for M.raptor and S.endius both mortality and progeny emergence per parasitoid did not increase notably above ratios of $1: 15$. In our experiments both the number of parasitoid progeny per parasitoid and the number of pupae killed per parasitoid did not significantly increase above parasitoid:host ratios between 1:10 and 1:20, depending upon the species.

The maximum number of pupae killed per parasitoid by S.endius (14.8) and M.raptor 
Table 2. Mean $( \pm$ SD) pupal mortality and parasitoid progeny emergence after 100 house fly pupae were exposed to varied densities of female parasitoids of four species of Pteromalidae for $24 \mathrm{~h}$.

\begin{tabular}{|c|c|c|c|c|c|c|c|}
\hline \multirow[b]{2}{*}{ Species } & \multirow[b]{2}{*}{$\begin{array}{l}\text { Parasitoid } \\
\text { density }\end{array}$} & \multirow[b]{2}{*}{$\begin{array}{l}\text { Parasitoid: } \\
\text { host ratio }\end{array}$} & \multicolumn{3}{|c|}{ Mean $\%$ of host pupae exposed* } & \multicolumn{2}{|c|}{ Mean no. per parasitoid* } \\
\hline & & & $\begin{array}{l}\text { Pupal mortality } \\
\text { (A) }\end{array}$ & $\begin{array}{l}\text { Parasitoid progeny } \\
\text { (B) }\end{array}$ & $\begin{array}{l}\text { Residual mortality } \\
(\mathrm{A}-\mathrm{B})\end{array}$ & $\begin{array}{l}\text { Pupae } \\
\text { killed }\end{array}$ & $\begin{array}{l}\text { Parasitoid } \\
\text { progeny }\end{array}$ \\
\hline \multirow[t]{5}{*}{ M.raptor } & 20 & $1: 5$ & $90.7 \pm 3.6^{\mathrm{a}}$ & $69.8 \pm 3.3^{\mathrm{a}}$ & $20.9 \pm 3.7^{\mathrm{a}}$ & $4.5 \pm 0.2^{\mathrm{b}}$ & $3.5 \pm 0.2^{\mathrm{b}}$ \\
\hline & 10 & $1: 10$ & $70.7 \pm 6.2^{\mathrm{b}}$ & $57.2 \pm 5.8^{\mathrm{ab}}$ & $13.5 \pm 3.5^{\mathrm{ab}}$ & $7.1 \pm 0.6^{\mathrm{b}}$ & $5.7 \pm 0.6^{\mathrm{b}}$ \\
\hline & 7 & $1: 14$ & $57.9 \pm 7.5^{\mathrm{b}}$ & $46.7 \pm 6.8^{\mathrm{b}}$ & $11.2 \pm 1.8^{\mathrm{b}}$ & $8.3 \pm 1.1^{\mathrm{b}}$ & $6.7 \pm 1.0^{\mathrm{ab}}$ \\
\hline & 5 & $1: 20$ & $39.4 \pm 2.9^{c}$ & $28.7 \pm 3.0^{\mathrm{c}}$ & $10.7 \pm 1.7^{\mathrm{b}}$ & $7.9 \pm 0.6^{\mathrm{b}}$ & $5.7 \pm 0.6^{\mathrm{b}}$ \\
\hline & 2 & $1: 50$ & $29.5 \pm 6.3^{\mathrm{c}}$ & $22.2 \pm 5.2^{\mathrm{c}}$ & $7.3 \pm 1.4^{\mathrm{b}}$ & $14.7 \pm 3.1^{\mathrm{a}}$ & $11.1 \pm 2.6^{\mathrm{a}}$ \\
\hline \multirow[t]{5}{*}{ M.zaraptor } & 20 & $1: 5$ & $96.4 \pm 1.1^{\mathrm{a}}$ & $74.2 \pm 2.3^{\mathrm{a}}$ & $22.2 \pm 1.9^{\mathrm{ab}}$ & $4.8 \pm 0.1^{\mathrm{b}}$ & $3.7 \pm 0.1^{\mathrm{b}}$ \\
\hline & 10 & $1: 10$ & $90.6 \pm 2.3^{\mathrm{a}}$ & $63.5 \pm 2.1^{\mathrm{ab}}$ & $27.1 \pm 2.1^{\mathrm{a}}$ & $9.1 \pm 0.2^{\mathrm{ab}}$ & $6.4 \pm 0.2^{\mathrm{ab}}$ \\
\hline & 7 & $1: 14$ & $69.6 \pm 7.5^{b}$ & $50.0 \pm 5.7^{\mathrm{bc}}$ & $19.6 \pm 2.3^{\mathrm{ab}}$ & $9.9 \pm 1.1^{\mathrm{ab}}$ & $7.1 \pm 0.8^{\mathrm{ab}}$ \\
\hline & 5 & $1: 20$ & $50.8 \pm 3.5^{\mathrm{b}}$ & $42.5 \pm 3.1^{\mathrm{c}}$ & $15.4 \pm 2.4^{\mathrm{b}}$ & $11.6 \pm 0.7^{\mathrm{a}}$ & $8.5 \pm 0.6^{\mathrm{a}}$ \\
\hline & 2 & $1: 50$ & $23.3 \pm 3.7^{\mathrm{c}}$ & $18.3 \pm 3.0^{\mathrm{d}}$ & $4.9 \pm 1.8^{\mathrm{c}}$ & $11.6 \pm 1.8^{\mathrm{a}}$ & $9.2 \pm 1.5^{\mathrm{a}}$ \\
\hline \multirow[t]{5}{*}{ S.cameroni } & 20 & $1: 5$ & $92.3 \pm 1.1^{\mathrm{a}}$ & $47.3 \pm 3.4^{\mathrm{a}}$ & $45.0 \pm 2.8^{\mathrm{a}}$ & $4.6 \pm 0.1^{\mathrm{d}}$ & $2.4 \pm 0.2^{\mathrm{b}}$ \\
\hline & 10 & $1: 10$ & $81.7 \pm 1.8^{b}$ & $38.1 \pm 3.2^{\mathrm{ab}}$ & $43.6 \pm 3.1^{\mathrm{a}}$ & $8.2 \pm 0.2^{\mathrm{c}}$ & $3.8 \pm 0.3^{\mathrm{ab}}$ \\
\hline & 7 & $1: 14$ & $67.4 \pm 2.2^{\mathrm{c}}$ & $30.4 \pm 1.9^{\mathrm{bc}}$ & $37.0 \pm 1.5^{\mathrm{a}}$ & $9.6 \pm 0.3^{\mathrm{bc}}$ & $4.3 \pm 0.3^{\mathrm{a}}$ \\
\hline & 5 & $1: 20$ & $60.0 \pm 3.7^{\mathrm{c}}$ & $26.4 \pm 1.7^{c}$ & $33.6 \pm 3.4^{\mathrm{ab}}$ & $12.0 \pm 0.7^{\mathrm{b}}$ & $5.3 \pm 0.3^{\mathrm{a}}$ \\
\hline & 2 & $1: 50$ & $33.9 \pm 2.4^{\mathrm{d}}$ & $11.0 \pm 1.5^{\mathrm{d}}$ & $22.9 \pm 2.4^{\mathrm{b}}$ & $16.9 \pm 1.3^{\mathrm{a}}$ & $5.5 \pm 0.7^{\mathrm{a}}$ \\
\hline \multirow[t]{5}{*}{ S.endius } & 20 & $1: 5$ & $85.9 \pm 3.0^{\mathrm{a}}$ & $63.4 \pm 3.4^{\mathrm{a}}$ & $22.5 \pm 2.0^{\mathrm{a}}$ & $4.3 \pm 0.2^{\mathrm{a}}$ & $3.2 \pm 0.2^{\mathrm{a}}$ \\
\hline & 10 & $1: 10$ & $55.9 \pm 7.0^{\mathrm{b}}$ & $33.7 \pm 8.4^{\mathrm{b}}$ & $22.2 \pm 4.4^{\mathrm{a}}$ & $5.6 \pm 0.7^{\mathrm{a}}$ & $3.4 \pm 0.8^{\mathrm{a}}$ \\
\hline & 7 & $1: 14$ & $48.6 \pm 9.5^{b}$ & $29.6 \pm 5.6^{\mathrm{bc}}$ & $19.0 \pm 4.4^{\mathrm{a}}$ & $7.0 \pm 1.4^{\mathrm{a}}$ & $4.2 \pm 0.8^{\mathrm{a}}$ \\
\hline & 5 & $1: 20$ & $42.0 \pm 5.8^{b}$ & $27.8 \pm 4.1^{\mathrm{bc}}$ & $14.2 \pm 2.1^{\mathrm{ab}}$ & $8.4 \pm 1.2^{\mathrm{a}}$ & $5.5 \pm 0.8^{\mathrm{a}}$ \\
\hline & 2 & $1: 50$ & $17.0 \pm 5.2^{\mathrm{c}}$ & $12.0 \pm 3.7^{\mathrm{c}}$ & $5.0 \pm 1.6^{\mathrm{b}}$ & $8.5 \pm 2.6^{\mathrm{a}}$ & $6.0 \pm 1.9^{\mathrm{a}}$ \\
\hline
\end{tabular}

* Means followed by the same letters in a column within a species were not significantly different $(P<0.05$, Tukey's procedure). 
Table 3. Mean ( \pm SD) pupal mortality and parasitoid progeny emergence after exposure of 240 house fly pupae for $24 \mathrm{~h}$ to twenty-four female parasitoids of two species of Pteromalidae at aggregation levels ranging from clumped (I) to uniform (IV).

\begin{tabular}{|c|c|c|c|c|c|c|}
\hline \multirow[b]{2}{*}{ Species } & \multirow[b]{2}{*}{$\begin{array}{l}\text { Pupal } \\
\text { aggregation }\end{array}$} & \multicolumn{3}{|c|}{ Mean \% of pupae exposed* } & \multicolumn{2}{|c|}{ No. per parasitoid* } \\
\hline & & $\begin{array}{l}\text { Pupal mortality } \\
\text { (A) }\end{array}$ & $\begin{array}{l}\text { Parasitoid progeny } \\
\text { (B) }\end{array}$ & $\begin{array}{l}\text { Residual mortality } \\
(\mathrm{A}-\mathrm{B})\end{array}$ & $\begin{array}{l}\text { Pupae } \\
\text { killed }\end{array}$ & $\begin{array}{l}\text { Parasitoid } \\
\text { progeny }\end{array}$ \\
\hline M.raptor & $\begin{array}{l}\text { I } \\
\text { II } \\
\text { III } \\
\text { IV }\end{array}$ & $\begin{array}{l}20.1 \pm 5.2^{\mathrm{a}} \\
46.7 \pm 5.8^{\mathrm{b}} \\
45.6 \pm 5.8^{\mathrm{b}} \\
42.6 \pm 4.1^{\mathrm{b}}\end{array}$ & $\begin{array}{l}17.4 \pm 5.0^{\mathrm{a}} \\
23.1 \pm 4.3^{\mathrm{a}} \\
25.1 \pm 3.4^{\mathrm{a}} \\
21.0 \pm 5.8^{\mathrm{a}}\end{array}$ & $\begin{array}{c}2.7 \pm 1.5^{\mathrm{a}} \\
23.6 \pm 5.8^{\mathrm{a}} \\
20.5 \pm 7.7^{\mathrm{a}} \\
21.6 \pm 6.4^{\mathrm{a}}\end{array}$ & $\begin{array}{l}2.0 \pm 0.5^{\mathrm{a}} \\
4.7 \pm 0.6^{\mathrm{b}} \\
4.6 \pm 0.6^{\mathrm{b}} \\
4.3 \pm 0.4^{\mathrm{b}}\end{array}$ & $\begin{array}{l}1.7 \pm 0.5^{\mathrm{a}} \\
2.3 \pm 0.4^{\mathrm{a}} \\
2.5 \pm 0.3^{\mathrm{a}} \\
2.1 \pm 0.6^{\mathrm{a}}\end{array}$ \\
\hline S.cameroni & $\begin{array}{l}\text { I } \\
\text { II } \\
\text { III } \\
\text { IV }\end{array}$ & $\begin{array}{l}20.5 \pm 8.0^{\mathrm{b}} \\
46.5 \pm 4.4^{\mathrm{a}} \\
48.2 \pm 6.0^{\mathrm{a}} \\
33.8 \pm 2.8^{\mathrm{ab}}\end{array}$ & $\begin{array}{r}14.4 \pm 3.1^{\mathrm{a}} \\
8.5 \pm 1.8^{\mathrm{a}} \\
8.2 \pm 2.1^{\mathrm{a}} \\
12.0 \pm 1.6^{\mathrm{a}}\end{array}$ & $\begin{array}{c}6.1 \pm 7.2^{\mathrm{b}} \\
38.0 \pm 2.9^{\mathrm{a}} \\
40.0 \pm 6.8^{\mathrm{a}} \\
21.8 \pm 2.6^{\mathrm{ab}}\end{array}$ & $\begin{array}{l}2.0 \pm 0.8^{\mathrm{b}} \\
4.7 \pm 0.4^{\mathrm{a}} \\
4.8 \pm 0.6^{\mathrm{a}} \\
3.4 \pm 0.3^{\mathrm{ab}}\end{array}$ & $\begin{array}{l}1.4 \pm 0.3^{\mathrm{a}} \\
0.9 \pm 0.2^{\mathrm{a}} \\
0.8 \pm 0.2^{\mathrm{a}} \\
1.2 \pm 0.2^{\mathrm{a}}\end{array}$ \\
\hline
\end{tabular}

* Means followed by the same letters in a column within a species were not significantly different $(P<0.05$, Tukey's procedure).

${ }^{\dagger}$ Distributions in a $1650 \mathrm{~cm}^{2}$ arena: $\mathrm{I}=240$ pupae in 1 cup; $I I=40$ pupae in each of 6 cups; III $=20$ pupae in each of 12 cups; IV = 10 pupae in each of 24 cups. 
(12.0) were similar to those (15 and 13 , respectively) reported by Morgan et al. (1979a, b). At densities of 150 and 200 hosts per cup, S.endius achieved both higher percentage pupal mortality and killed more pupae per parasitoid than any other species, supporting the suggestion that S.endius has a high attack potential at high host densities (Ables \& Shepard, 1974; Legner, 1967).

Both discrimination of previously parasitized pupae and ovipositional restraint have been shown for each of the species used in our experiments (Wylie, 1971, 1972; Propp \& Morgan, 1985). Assuming that successful development from egg to adult is not directly density dependent, at low host densities (where competition for hosts is high) changes in percentage residual mortality reflect changes in ovipositional restraint. In M.raptor there was a significant increase in the percentage residual mortality at ten hosts per cup compared to those at 50-200 hosts per cup, suggesting a breakdown in ovipositional restraint. Pawson et al. (1987) reported similar results with $M$.zaraptor and low host densities, which indicates that this is a common phenomenon. Both Spalangia species exhibited a higher overall percentage residual mortality than Muscidifurax. It was not possible to determine from these experiments whether this was caused by higher levels of host-feeding, superparasitism or unsuccessful oviposition.

In our experiments using varied densities of parasitoids, the percentage pupal mortality due to parasitism and the number of pupae killed per parasitoid were comparable to values in the first set to experiments with variable densities of hosts. Mean values for percentage parasitoid progeny emergence and parasitoid progeny per parasitoid were similar in both experiments for all species except S.endius. Percentage residual mortality increased with parasitoid density in all species, although values were consistently higher in S.cameroni. Increased parasitoid densities did not result in consistent increases in the number of pupae killed per parasitoid or progeny per parasitoid in any species except S.endius. It was therefore assumed that parasitoid interference had not affected parasitoid induced pupal mortality nor parasitoid emergence in M.raptor, M.zaraptor and S.cameroni although it may have reduced the magnitude of the response in S.endius.

M.raptor and S.cameroni exhibited a similar response to host aggregation. Levels of host mortality were similar for both species, at each distribution, indicating similar searching abilities. Our data support the field-collected data presented by Propp \& Morgan (1985), suggesting that parasitoids did not show a density dependent response to spatial variation in host densities. At the highest level of host aggregation, although there was potential for parasitoid aggregation, the percentage residual mortality decreased, possibly due to ovipositional restraint and/or an increased tendency to disperse (Nagel \& Pimentel, 1963).

The density-dependence of host mortality and parasitoid progeny emergence in pteromalid parasitoids has been clearly demonstrated under laboratory conditions. Under field conditions, Propp \& Morgan (1985) did not find sủch a relationship to host spatial density, however. Other factors such as time and temperature have been shown to influence the parasitoid response to host density in pteromalid and other chalcid wasps (Burnett, 1951, 1954; Legner, 1967). An understanding of the interactions of all these factors will allow more accurate determination of the regulation of house fly populations by pteromalid parasitoids.

\section{Acknowledgments}

The authors thank T. D. Edwards for assisting in rearing the insects and construction of chambers. This is Paper No. 12191 of the Journal Series of the North Carolina Agricultural Research Service, Raleigh, N.C., U.S.A. This research was supported in part by USDACooperative States Research Service Grants No. 86-CSRS-2-2889 and 89-34103-4240.

\section{References}

Abbott, W.S. (1925) A method of computing the effectiveness of an insecticide. Journal of Economic Entomology, 18, 265-267.

Ables, J.R. \& Shepard, M. (1974) Responses and competition of the parasitoids Spalangia endius and Muscidifurax raptor (Hymenoptera: Pteromalidae) at different densities of house fly pupae. Canadian Entomologist, 106, 825-830.

Axtell, R.C. (1986a) Fly management in poultry production: Cultural, biological and chemical. Poultry Science, 65, 657-667. 
Axtell, R.C. (1986b) Fly control in confined livestock and poultry production. Technical Bulletin, CibaGeigy Corporation, Greensboro, North Carolina 27419, U.S.A., 59pp.

Burnett, T. (1951) Effects of temperature and host density of the rate of increase of an insect parasite. American Naturalist, 85, 337-52.

Burnett, T. (1954) Influences of natural temperatures and controlled host density on oviposition of and insect parasite. Physiological Zoology, 27, 239-248.

DeBach, P. \& Smith, H. (1941) The effect of host density on the rate of reproduction of entomophagous parasites. Journal of Economic Entomology, 34, 741-745.

Hassel, M.P. (1978) The Dynamics of Arthropod Predator-Prey Systems. Princeton University Press.

Hassel, M.P. \& Waage, J.K. (1984) Host-parasitoid population interactions. Annual Review of Entomology, 29, 89-114.

Holling, C.S. (1959) The components of predation as revealed by a study of small mammal predation of the European pine sawfly. Canadian Entomologist, 91, 292-320.

Jones, T.H. \& Turner, B.D. (1987) The effect of host spatial distribution on patterns parasitism by Nansonia vitripennis. Entomologia Experimentalis et Applicata, 44, 169-175.

Legner, E.F. (1967) Behaviour changes in the reproduction of Spalangia cameroni, Spalangia endius, Muscidifurax raptor and Nansonia vitripennis (Hymenoptera: Pteromalidae) at increasing fly host densities. Annals of the Entomological Society of America, 60, 819-826.

Legner, E.F. (1969) Distribution pattern of hosts and parasitization by Spalangia drosophilae (Hymenoptera: Pteromalidae). Canadian Entomologist, 101, 551-557.

Morgan, P.B., LaBreque, G.C., Weidhaas, D.E. \& Patterson, R.S. (1979a) Interrelationship between two specics of muscoid flies and the pupal parasite Spalangia endius (Hymenoptera: Pteromalidae). Journal of Medical Entomology, 16, 331-334.

Morgan, P.B., Weidhaas, D.E. \& LaBrecque, G.C. (1979b) Host-parasite relationship of the house fly Musca domestica L., and the microhymenopterous pupal parasite Muscidifurax raptor Girault and Sanders (Diptera: Muscidae and Hymenoptera: Pteromalidae). Journal of the Kansas Entomological Society, 52, 276-281.

Nagel, W.P. \& Pimentel, D. (1963) Some ecological attributes of a pteromalid parasite and its house fly host. Canadian Entomologist, 95, 208-213.

Patterson, R.S. \& Rutz, D.A. (eds) (1986) Biological control of muscoid flies. Entomological Society of America Miscellaneous Publications, 61, 1-174.

Pawson, B.M., Petersen, J.J. \& Holtzer, T.O. (1987) Competitive parasitism of house fly pupae (Diptera: Muscidae) by Muscidifurax zaraptor and Urolepis rufipes (Hymenoptera: Pteromalidae). Journal of Medical Entomology, 24, 66-70.

Propp, G.D. \& Morgan, P.B. (1985) Effect of host distribution on parasitoidism of house fly (Diptera: Muscidae) pupae by Spalangia species and Muscidifurax raptor (Hymenoptera: Pteromalidae). Canadian Entomologist, 117, 515-524.

SAS Institute (1982) SAS User's Guide: Statistics. SAS Institute, Cary, North Carolina, U.S.A.

Walde, S.J. \& Murdoch, W.W. (1988) Spatial density dependance in parasitoids. Annual Review of Entomology, 33, 441-66.

Wylie, H.G. (1971) Oviposition restraint of Muscidifurax zaraptor (Hymenoptera: Pteromalidae) on parasitized house fly pupae. Canadian Entomologist, 103, 1537-1544.

Wylie, H.G. (1972) Oviposition restraint of Spalangia cameroni (Hymenoptera: Pteromalidae) on parasitized house fly pupae. Canadian Entomologist, 104, 209-214.

Accepted 28 September 1989. 